\title{
The experimental determination of heat transfer and pressure drop during condensation in a plate heat exchanger with corrugated plates
}

\author{
A. Müller ${ }^{1} \&$ S. Kabelac ${ }^{2}$ \\ ${ }^{1}$ Helmut-Schmidt-University, \\ University of the Federal Armed Forces Hamburg, Germany \\ ${ }^{2}$ Leibniz University of Hannover, Germany
}

\begin{abstract}
Plate heat exchangers (PHE) are well established apparatuses with a broad field of application due to their high thermal efficiency, compactness and cost competitiveness. The objective of this work is the experimental investigation of two-phase heat transfer and pressure drop during condensation in a vertical corrugated plate gap. The apparatus used in the experiments is a three-stream PHE of plate and frame construction with two heat transfer sections and an intermediate plate. Experiments are conducted using two different chevron angles $\left(27^{\circ}\right.$ and $\left.63^{\circ}\right)$. The heat transfer coefficients are determined by local recording of wall and fluid temperatures for obtaining differential energy balances. Based on the measured integral pressure drop across the apparatus the pressure gradient in the plate gap is recalculated locally by an adapted two-phase calculation model, combining the homogenous and heterogeneous model. As working fluids the refrigerant R134a and steam are used. For both working fluids the results for the two plate types are compared and the influence of the chevron angle on heat transfer and pressure loss is emphasized.

Keywords: heat exchanger, condensation, multistream, refrigerant R134a, water steam.
\end{abstract}




\section{Introduction}

PHE are more and more frequently used as condensers, due to their compact design and high thermal efficiency. The discontinuous temperature curve caused by the successive desuperheating, condensation and subcooling of the working medium prevents an energy-optimized design of the condenser. However, the reduction of the temperature differences in heat exchangers is usually advantageous in terms of energetic and exergetic efficiency. The lack of reliable correlations for prediction of condensation heat transfer and pressure drop in PHE available in the literature often leads to incorrect sizing of the apparatus. This causes a loss in thermal efficiency either because of rising temperature differences or because of strong subcooling of the condensate. The main objective of this work therefore is the experimental investigation of the condensation heat transfer and pressure drop to provide data for the adaption of heat transfer and pressure loss calculation models. Beside the number of plates their specific design has a significant influence on the thermal performance. Here the influence of the corrugation angle is highlighted; Plates with corrugation declination angles of $\varphi<45^{\circ}$ to the main flow direction are named as low plates (v) while plates with $\varphi>45^{\circ}$ are named as high plates (h). The longer flow path and the higher turbulence caused by the deflections in the plate channel of the h-plates result in higher heat transfer and pressure drop rates compared to the v-plates. Two different chevron plate types are used for both sections.

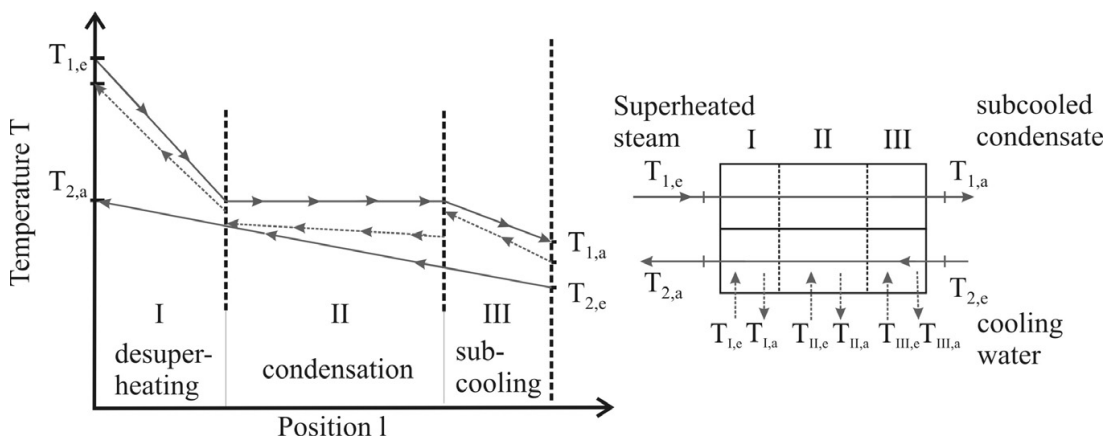

Figure 1: Idealized temperature profile of the desuperheating, condensation and subcooling of a working medium by one or three coolants.

The second objective is the optimization of the condensation process in PHE by splitting the cooling water stream as demonstrated in Figure 1 to minimize the temperature differences. The idealized temperature curve of the working medium is represented by the top solid curve. Desuperheating takes place in sec. I, condensation in sec. II and subcooling in sec. III. If one coolant (lower solid curve) is used for the whole process, there will be a pinch point at the beginning of the condensation process at the switchover from sec. I to sec. II. Large 
temperature differences appear at the entrance of the superheated vapour stream and at the end of the condensation section. By using three (dashed curves) instead of one coolant the temperature differences can be minimized in every single section and thereby for the whole process. For practical applications an optimal design of the different sections will enhance the thermal efficiency. This process can be realized by three apparatuses in succession or, as proposed here, by one adjusted apparatus. In this work a Multistream-PHE with two heat transfer sections (sec. I and II) is used. Two different chevron plate types are used for both section I and II. As the condensation in sec. II is nearly free from the influence of desuperheating and subcooling the condensation process can be analyzed to obtain heat transfer and pressure drop correlations. The experimental results are validated by comparison with data from literature.

\section{Literature}

Heat transfer and pressure drop for the condensation of R134a in a PHE was investigated experimentally by Yang et al. [1]; a Dittus-Boelter-correlation is given for calculating the heat transfer. Shah and Focke [2] give a calculation model for heat transfer between plates, validated by data from literature. An empirical correlation for the convective condensation heat transfer has been derived by Boyko and Kruzhilin [3], in which the condensation heat transfer is calculated by multiplication of the single phase heat transfer with a coefficient. The advantage of this model procedure is that only the single phase heat transfer characteristics have to be known for a specific apparatus or working fluid. Wang and Sunden [4] carried out condensation experiments using steam. They also presented a method for prediction of pressure drop for full or partial condensation, the model of Lockhart and Martinelli [5] is adapted. Two-phase flow of liquid water and air in a plate gap has been studied by Tribbe and Müller-Steinhagen [6] for two different plate types and pressure drop correlations are given. Condensation of refrigerants in PHE was investigated by Grabenstein [7] in a single plate gap and a PHE in industrial scale, providing calculation models for local and integral heat transfer and pressure drop. Besides, a broad overview of literature for condensation in PHE is given.

\section{Experimental set up}

In this work a plate and frame PHE of industrial scale is used. An intermediate plate separates the heat transfer area in two main sections as depicted in Figure 2, and two cooling water streams are used for desuperheating und condensing.

Independent variation of flow direction of cooling water, number of plates and plate type in the sections is possible. The intermediate plate offers additional inlet and outlet manifolds and is also thermally isolating the sections from each other. Either steam or R134a is used as working fluid. Plates with $\varphi_{\mathrm{v}}=27^{\circ}$ and $\varphi_{\mathrm{h}}=63^{\circ}$ are chosen, the other parameters of the plates are the same for both 


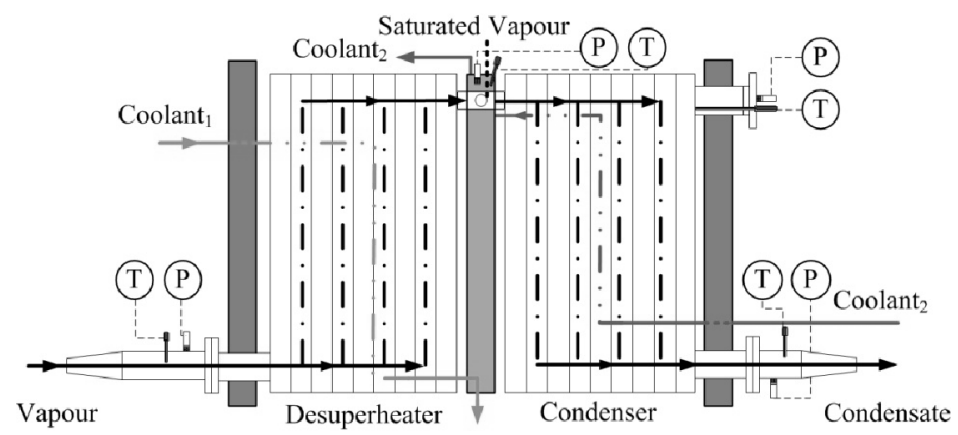

Figure 2: Multistream-PHE with two sections and an intermediate plate.

Table 1: Plate properties.

\begin{tabular}{clcc}
\hline Symbol & denotation & Value & SI-unit \\
\hline$\varphi$ & Corrugation angle & 63 or 27 & $\circ$ \\
$L_{\mathrm{port}}$ & Distance between center of separator and center of & 1.113 & $\mathrm{~m}$ \\
$L_{\mathrm{t}}$ & collector & 0.936 & $\mathrm{~m}$ \\
$L_{\mathrm{p}}$ & Length of heat transfer area & 0.814 & $\mathrm{~m}$ \\
$B_{\mathrm{p}}$ & Width of wave field & 0.386 & $\mathrm{~m}$ \\
$\lambda_{\mathrm{p}}$ & Thermal conductivity & 15 & $\mathrm{~W} / \mathrm{mK}$ \\
$\mathrm{b}$ & Height of plate gap & 3 & $\mathrm{~mm}$ \\
$\delta_{\mathrm{p}}$ & Plate thickness & 0.6 & $\mathrm{~mm}$ \\
$\Lambda$ & Wave length of corrugation & 11.4 & $\mathrm{~mm}$ \\
$\phi$ & Surface enlargement factor & 1.155 & - \\
$d_{\mathrm{h}}$ & Hydraulic diameter & 5.194 & $\mathrm{~mm}$ \\
- & Material & 1.4404 & - \\
\hline
\end{tabular}

plate versions, they are summarized in Table 1. The Multistream-PHE was first integrated into a refrigeration circuit which had previously been used for condensation and evaporation experiments with R134a and Ammonia by André [8], Djordjevic et al. [9] and Grabenstein [7]. The design of the refrigeration circuit is described in detail in these references. The maximum cooling capacity is $\dot{Q}_{\mathrm{K}}=100 \mathrm{~kW}$ and the maximum compressor power is $\mathrm{P}^{\mathrm{el}}=55 \mathrm{~kW}$. After the condensation experiments with R134a a new experimental setup has been built up for steam condensation. A gas boiler with a maximum heating power of about 1 MW generates steam that is desuperheated and condensed in the MultistreamPHE as depicted in Figure 2 by two closed cooling water loops. A steam trap at the condenser outlet ensures complete condensation. The working fluid (R134a or steam), which is superheated up to $60 \mathrm{~K}$ in both cases, flows upwards in the desuperheating section (sec. I). Nearly saturated, with a low residual superheating of 1-3 K, the vapour flows through the intermediate plate where temperature and pressure measuring points are implemented. A sight glass allows visual inspection to detect premature condensation. The vapour is then 
condensed and slightly subcooled by $3-6 \mathrm{~K}$ in sec. II. The experiments were performed in the parameter range shown in Table 2.

Table 2: Parameter range of the condenser for all experiments.

\begin{tabular}{cccccc}
\hline & Plate type & $\begin{array}{c}\text { Channels at } \\
\text { condensation side }\end{array}$ & $G\left[\mathrm{~kg} / \mathrm{m}^{2} \mathrm{~s}\right]$ & $\dot{q}\left[\mathrm{~kW} / \mathrm{m}^{2}\right]$ & $p_{\text {cond }}[\mathrm{kPa}]$ \\
\hline R134a & $\mathrm{h}\left(63^{\circ}\right)$ & $5-30$ & $5-55$ & $1.3-15.5$ & $467-900$ \\
& $\mathrm{v}\left(27^{\circ}\right)$ & 8 & $20-37$ & $5.8-10$ & $613-734$ \\
\hline \multirow{2}{*}{ Steam } & $\mathrm{h}\left(63^{\circ}\right)$ & $3-8$ & $10-36$ & $37-114$ & $110-200$ \\
& $\mathrm{v}\left(27^{\circ}\right)$ & 8 & $10-34$ & $37-103$ & $100-200$ \\
\hline
\end{tabular}

\section{Measuring data acquisition and data evaluation}

For the integral energy balances of the fluids, the temperatures, pressures, volume and mass flows at the inlet and outlet ports are measured. The in- and outlet temperature of the fluids are measured using PT100 resistance thermometers with a precision of $\pm 0.05 \mathrm{~K}$. For the working media there are two PT100 at the inlet, outlet and at the intermediate plate which is the outlet of sec. I and the inlet of sec. II at the same time. The integral energy balances of the condenser can be closed within 3\% for R134a, while the higher temperature level of the steam condensation causes heat losses to the environment and a deviation up to $10 \%$. The absolute pressure and the pressure difference between in- and outlet of a section have been measured with membrane pressure sensors with an accuracy class of $0.1 \%\left(p_{\text {abs }}\right)$ und $0.2 \%\left(\Delta p_{\text {diff }}\right)$. The connecting pipes of the differential pressure sensors have been thermally isolated and heated to avoid condensation inside the pipes for the R134a experiments. However, in the steam experiments temperatures are too high to ensure that no condensation inside the connecting pipes takes place. Thus, the absolute pressure is measured at inlet, intermediate plate and outlet instead. Mass flow of the condensate is measured with a coriolis mass flowmeter with an accuracy of $0.2 \%$, while the volume flow of the cooling water is measured by impeller flowmeters. Their measurement uncertainty of $3 \%$ has been reduced to their repeatability accuracy of $0.5 \%$ by careful calibration. In the channels of the coolants thermocouples (type K, 0.5 $\mathrm{mm}$ diameter) have been installed to obtain local, section wise energy balances. The thermocouples are brazed to the plate's surface along the flow path to measure the fluid and the wall temperature for direct calculation of the heat transfer coefficient of the cooling water. After brazing them to the plates surface, the thermocouples where calibrated inside a tempered water basin to obtain an uncertainty of $\pm 0.1 \mathrm{~K}$ for the local temperature measurement.

\section{Calculation of heat transfer and pressure drop}

Inside the channels the temperature can only be measured at the cooling fluid side. The temperature of the condensing fluid is only accessible at the inlet and the outlet of the manifolds because of the necessary leak tightness. 


$$
\begin{gathered}
A_{\mathrm{l}}=2 L_{\mathrm{l}} B_{\mathrm{p}} \phi \\
\alpha_{\text {cond,l }}\left(x_{\mathrm{m}, \mathrm{l}}\right)=\frac{\dot{q}_{\mathrm{c}, \mathrm{l}}}{T_{\text {cond,l }}^{\text {sat }}\left(p_{\text {cond,l }}^{\text {sat }}\right)-T_{\text {cond,wl } \mathrm{l}}} \\
\mathrm{Nu}_{\text {cond,exp }}=\frac{\alpha_{\text {cond,exp }} d_{\mathrm{h}}}{\lambda_{\text {liq }}}
\end{gathered}
$$

From the temperature difference between two measuring points in the channel the heat flux $\dot{q}_{c, 1}$ into the cooling water in the segment is calculated. The heat transfer area $A_{1}$ of the plates is calculated following the procedure discussed in VDI-Wärmeatlas [10]. For the segment with the length $l$, the heat transfer area is calculated from eqn (1). The heat transfer coefficient $\alpha_{\mathrm{c}, \mathrm{l}}$ of the coolant is calculated independently of any single phase correlation from $\dot{q}_{\mathrm{c}, \mathrm{l}}$ and the logarithmic mean temperature difference $\Delta T_{\ln }$ of the measured wall- and fluid temperatures. The wall temperature on the condensation side is calculated from the heat flux and the average wall temperature on the coolant side. For every segment $x_{\mathrm{m}, \mathrm{l}}$ is received from local energy balances. In Figure 3 two plate gaps are depicted to show the position of the thermocouples. The squares mark the temperatures in the middle of the plate gap. On the condensation side this temperatures are a function of the local saturation pressure and therefore depend on the pressure loss. The correct determination of the pressure gradient in the channel is important both for the calculation of the local condensation heat transfer coefficients at a segment and the average steam mass fraction. The local heat transfer coefficients for condensation can be averaged for the full condensation and the local or integral Nusselt number is obtained from eqn (3).

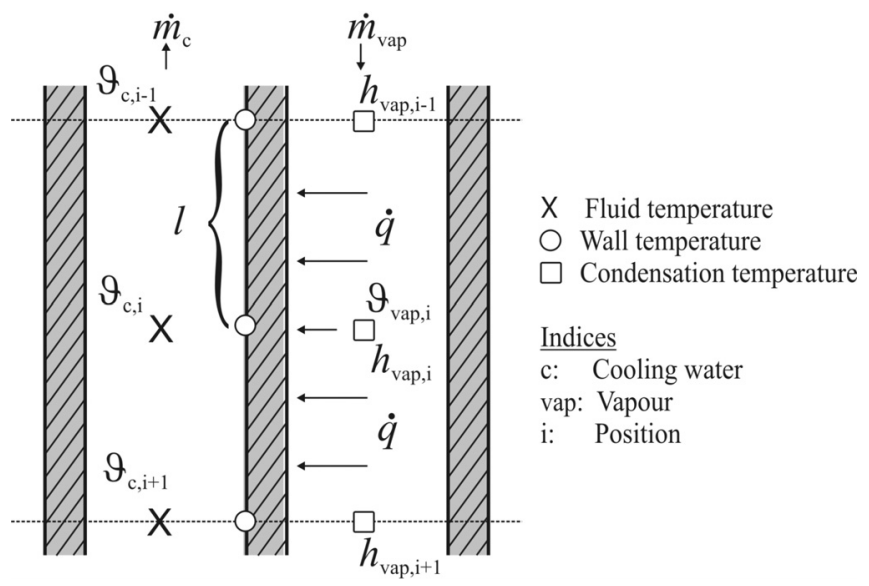

Figure 3: Position of local temperature measurement. 


\subsection{Pressure gradient in the channel}

For the determination of the condensation heat transfer coefficients, the pressure curve in the channel is determined to obtain the local condensation temperatures.

$$
\begin{gathered}
\Delta p_{\mathrm{R}, 2 \mathrm{ph}}=\Delta p_{\text {meas }}-\Delta p_{\text {man }}+\Delta p_{\text {stat }}+\Delta p_{a c c} \\
\Delta p_{\text {man }}=1,4 G_{\text {man }}^{2} /\left(2 \varrho_{\mathrm{m}}\right) \\
\Delta p_{\text {stat }}=\varrho_{\mathrm{m}} g \Delta \mathrm{z} \\
\Delta p_{\text {acc }}=\frac{G \Delta x}{\varrho_{\mathrm{m}}} \\
\varrho_{\mathrm{m}}=\left(\frac{x}{\varrho_{\text {vap }}}+\frac{1-x}{\varrho_{\text {liq }}}\right)^{-1}
\end{gathered}
$$

The high volume flows and the slope of the vapour pressure curve of the steam cause much higher deviations of the saturation temperature $\mathrm{T}^{\mathrm{sat}}$ compared to R134a. A maximum change in $\mathrm{T}^{\text {sat }}$ of $25 \mathrm{~K}$ between in- and outlet of sec. II has been observed, while the deviation of $\mathrm{T}^{\text {sat }}$ was less than $1 \mathrm{~K}$ in all cases for R134a. Between the measurement points at the intermediate plate and the outlet of sec II the local pressure in the plate channel is determined from eqns (4)-(8). From the measured pressure difference $\Delta p_{\text {meas }}$ the frictional pressure drop $\Delta p_{\mathrm{R}, 2 \mathrm{ph}}$ is calculated by eqn (4). In eqn (5) the pressure loss $\Delta p_{\text {man }}$ in the manifolds is calculated following Kakac and Liu [11]. The static pressure change $\Delta p_{\text {stat }}$ is taken from eqn (6) and the acceleration pressure change $\Delta p_{\text {acc }}$ in eqn (7) is calculated with the mean density according to the homogeneous model as shown in eqn (8). A variation of flow types (annular-, mist- or film- flow) can be expected in the channels of a PHE and the vapour and liquid phase in many cases will be separated flows. Nevertheless the calculation of the condensation heat transfer coefficient and pressure drop by the homogenous model is applicable if the thermodynamic properties are averaged in a proper manner.

$$
\begin{aligned}
& \operatorname{Re}_{\mathrm{hom}}=G d_{h} / \eta_{2 \mathrm{ph}, \mathrm{hom}} \\
& \eta_{2 \mathrm{ph}, \mathrm{hom}}=\left(\frac{x}{\eta_{\mathrm{vap}}}+\frac{1-x}{\eta_{\text {liq }}}\right)^{-1} \\
& \xi_{2 \mathrm{ph}, \mathrm{hom}}=\frac{2 \Delta p_{\mathrm{R}, 2 \mathrm{ph} \varrho_{\mathrm{m}} d_{\mathrm{h}}}}{G^{2} L_{\mathrm{p}}}
\end{aligned}
$$

The average Reynolds number $\mathrm{Re}_{\text {hom }}$ in eqn (9) can be calculated locally or integrally from the mass flow density $G$, the hydraulic diameter $d_{\mathrm{h}}$ and the dynamic viscosity $\eta$ that is determined with respect to the steam content in eqn (10). The friction pressure loss coefficient $\xi_{2 \mathrm{ph} \text {,hom }}$ of the homogeneous model in eqn (11) is correlated with the average Reynolds number $\mathrm{Re}_{\mathrm{hom}}$. The results 
for $\xi_{2 \text { ph,hom }}$ following the Blasius approach and Nusselt correlations of DittusBoelter approach are summarized in Table 3.

The frequent deflections in the plate gap lead to good mixing and breakup of the phase boundaries. However, by visualization at a single transparent plate channel Grabenstein [7] showed that for high void fractions during condensation in PHE heterogeneous flow pattern occur. For heterogeneous multiphase flow Akers et al. [12] proposed the application of the equivalent mass flow $G_{\text {eq }}$ in eqn (12) and the equivalent Reynolds number $\operatorname{Re}_{\mathrm{eq}}$ in eqn (13). In this way the high sensibility of the system to the influence of the density ratio between vapour and liquid is taken into account. At high void fractions at the inlet of the channel, heterogeneous flow pattern can be expected, while homogeneous flow is likely at lower void fractions. To calculate the local pressure in the channel Grabenstein [7] proposed the combination of the heterogeneous and homogeneous models (eqn 18) weighted by the steam content.

Table 3: Condensation frictional pressure loss coefficients of the homogeneous model.

\begin{tabular}{|c|c|c|c|c|}
\hline $\begin{array}{c}\text { Plate } \\
\text { type }\end{array}$ & $\begin{array}{c}\text { Friction pressure } \\
\text { loss coefficient, } \\
\text { total condensation }\end{array}$ & $\begin{array}{c}\text { Average } \\
\text { deviation }\end{array}$ & $\begin{array}{c}\text { Heat transfer coefficient, } \\
\text { complete condensation }\end{array}$ & $\begin{array}{c}\text { Average } \\
\text { deviation }\end{array}$ \\
\hline- & $\xi_{\text {hom }}$ & $\%$ & $\mathrm{Nu}$ & $\%$ \\
\hline $\mathrm{h}\left(63^{\circ}\right)$ & $13.13 \cdot \mathrm{Re}_{\mathrm{m}}{ }^{-0.200}$ & 8.6 & $\begin{array}{c}\text { R134a: } 0.501 \cdot \mathrm{Re}_{\mathrm{eq}}{ }^{0.624} \mathrm{Pr}_{\text {liq }}{ }^{0.4996} \\
\text { Steam: } 0.501 \cdot \mathrm{Re}_{\mathrm{eq}}{ }^{0.55} \mathrm{Pr}_{\text {liq }}{ }^{0.496}\end{array}$ & $\begin{array}{c}13.8 \\
7.41\end{array}$ \\
\hline $\mathrm{v}\left(27^{\circ}\right)$ & $5.00 \cdot \mathrm{Re}_{\mathrm{m}}{ }^{-0.240}$ & 11.7 & Both: $1.061 \cdot \mathrm{Re}_{\mathrm{eq}}{ }^{0.445} \operatorname{Pr}_{\mathrm{liq}}{ }^{0.541}$ & 12.9 \\
\hline
\end{tabular}

$$
\begin{gathered}
G_{\mathrm{eq}}=G\left((1-x)+x\left(\frac{\varrho_{\text {liq }}}{\varrho_{\text {vap }}}\right)^{0,5}\right) \\
\operatorname{Re}_{\mathrm{eq}}=G_{\mathrm{eq}} d_{\mathrm{h}} / \eta_{\text {liq }} \\
\Delta p_{\mathrm{R}, 2 \mathrm{ph}}=x \Delta p_{\mathrm{R}, \mathrm{het}}+(1-x) \Delta p_{\mathrm{R}, \mathrm{hom}}
\end{gathered}
$$

\section{Results and discussion}

The energetic or cost specific optimized design of a PHE depends on the availability of reliable correlations to calculate heat transfer and pressure drop during condensation. The experimental data have been analyzed to show the influence of important factors like the mass flow rate, the pressure and the heat flux. The local calculation of the heat transfer as described in subsection 5 allows the determination of the influence of the condensation pressure. As shown in Figure 4, at the same mass flow density a lower condensation pressure results in an increased heat transfer and a more rapid decrease of the steam content. The results of the three experimental points are summarized in Table 4. 


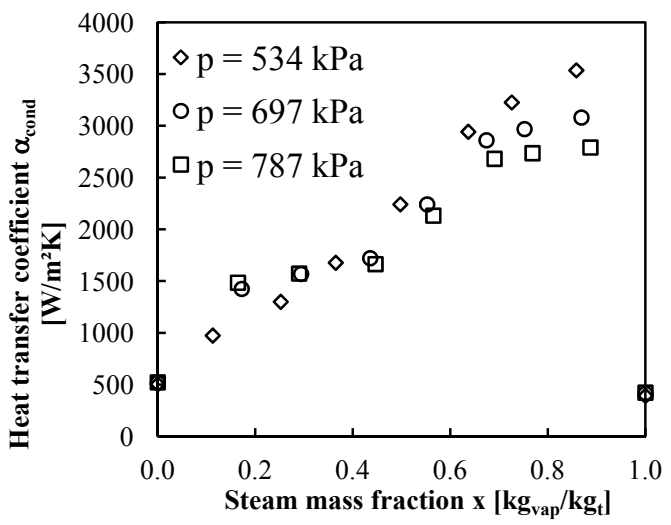

Figure 4: Local heat transfer coefficients, condensation of R134a, $\dot{q}=8$ $\mathrm{kW} / \mathrm{m}^{2}, G=29 \mathrm{~kg} / \mathrm{m}^{2} \mathrm{~s}$.

For the vapour content $x^{*}=0$ and $x^{*}=1$, the heat transfer coefficient of the single-phase flow is shown as a comparison value. In Figure 4 the heat transfer increases rapidly at the beginning of condensation and then decreases with falling steam mass fractions until the heat transfer of the pure liquid phase is reached. This effect is taken into account in eqn (12) for the calculation of the equivalent mass flow density.

Table 4: Parameter and results of three data points.

\begin{tabular}{cccc}
\hline $\begin{array}{c}p_{\text {cond }} \\
\mathrm{kPa}\end{array}$ & $\begin{array}{c}\alpha_{\text {cond }} \\
\mathrm{W} / \mathrm{m}^{2} \mathrm{~K}\end{array}$ & $\begin{array}{c}\Delta p_{\mathrm{R}} \\
\mathrm{kPa}\end{array}$ & $\begin{array}{c}x_{\mathrm{m}, \mathrm{l}} \\
\mathrm{kg}_{\text {vap }} / \mathrm{kg}_{\mathrm{t}}\end{array}$ \\
\hline 787 & 2289.8 & 3.1 & 0.54 \\
697 & 2317.0 & 4.2 & 0.54 \\
534 & 2334.9 & 4.6 & 0.49 \\
\hline
\end{tabular}

\subsection{Heat transfer of the refrigerant R134a}

The experimental heat transfer coefficients are compared with data from literature in Figure 5. Using the correlation of Boyko and Kruzhilin [3] higher heat transfer coefficients $(>+15 \%)$ are predicted compared with the experimental data. The correlation by Shah and Focke [2] for vertical plates is consistent $( \pm 15 \%)$ for more than $50 \%$ of the test data, the other data are predicted within $\pm 30 \%$. The Nusselt numbers calculated from the correlation of Yang et al. [1] are in good agreement with the experimental data for $\mathrm{Nu}_{\text {exp }}>60$, increasing deviations towards smaller Nusselt numbers are found. The Grabenstein [7] correlation for h-plates predicts lower heat transfer for nearly the whole parameter range. For the v-plates with the correlating of Boyko and Kruzhilin [3] heat transfer twice as high as the experimental data is predicted. A good agreement within 10\% with the Grabenstein [7] correlation for v-plates is 
achieved. In comparison, the heat transfer of the h-plates is 3-4 times larger than that of the v-plates.

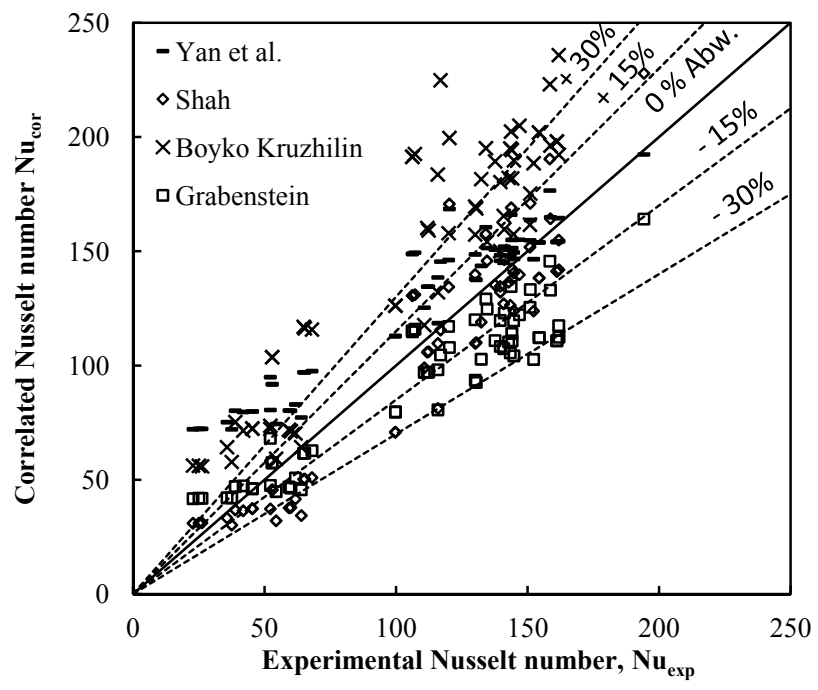

Figure 5: Experimental heat transfer coefficients compared to correlations from literature.

\subsection{Results of the pressure loss analysis}

The condensation frictional pressure loss is determined from the experimental data for the h- and v-plate type and both working media, plotted versus the equivalent mass flow density in Figure 6. The friction pressure loss of the steam is an order of magnitude higher than that of the R134a due to the high volume flows. For both refrigerant and steam the frictional pressure loss at full condensation in the h-plate is around 3-4 times higher than in the v-plate, a dependency that has already been noted by Bassiouny [14]. Following Wang and Zhao [15] an average vapour mass fraction of $x_{\mathrm{m}}=0.54$ was assumed for the calculation of the pressure loss based on correlations, in good agreement with our analysis of the condensation experiments, as shown for instance in Table 4. Wang and Sunden [4] adapted the method of Lockhart and Martinelli [5] and the correlation of Chisholm [13] for calculation of the condensation friction pressure loss. Higher pressure losses are predicted in this way compared to the heterogeneous model of Tribbe and Müller-Steinhagen [6]. As shown in Figure 7 for the v-plates $\left(27^{\circ}\right)$, the pressure loss predictions of the homogeneous model lie between the values of the different heterogeneous models. The combination of the heterogeneous model of Wang and Sunden [4] and the homogeneous model according to eqns (8)-(11) is giving the best results with the lowest average mean deviation compared to the experimental results and nearly all predictions are within $\pm 20 \%$. The results for the h-plates are similar, but the deviations of 
the heterogeneous Model of Wang and Sunden [4] are higher $(+24 \%)$, while the same accuracy for the model of Tribbe and Müller-Steinhagen [6] is found for h- and v-plates with negative deviations from the experimental data of less than $15 \%$.

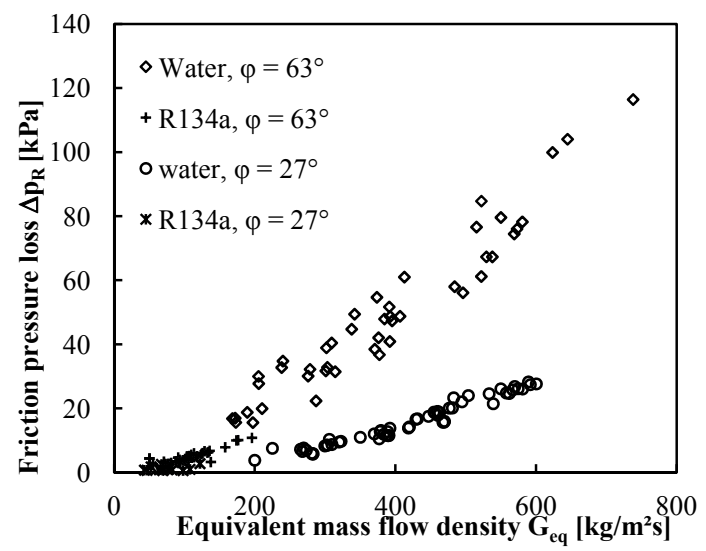

Figure 6: Experimental friction pressure loss, comparison of plate types and media.

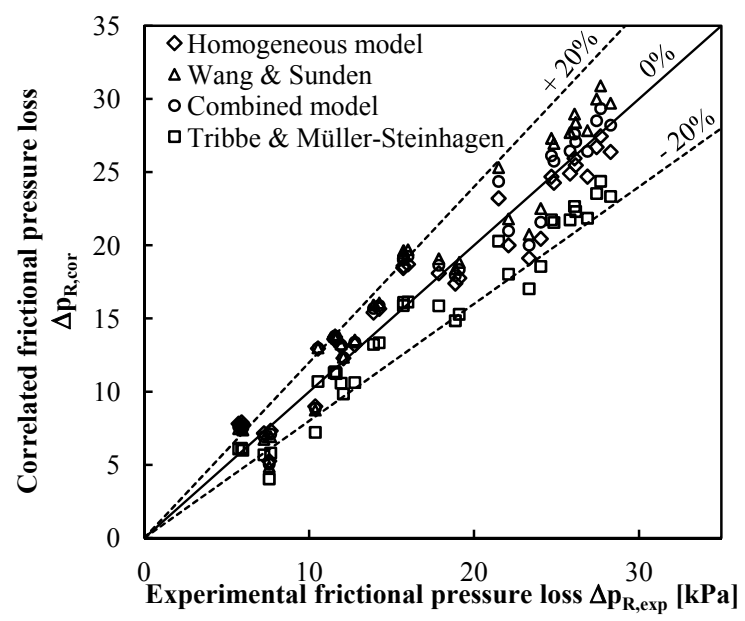

Figure 7: Comparison of experimental pressure loss data with model predictions.

\section{Conclusions}

The condensation heat transfer and pressure drop in a PHE was examined experimentally and the influence of the corrugation angle, the mass flow density and the absolute pressure level was outlined. The integral heat transfer 
coefficient during condensation of R134a was validated with data from the literature. The condensation pressure drop can be predicted with an accuracy of \pm $20 \%$. Correlations for integral heat transfer and pressure drop calculations are given. The temperature profile in the desuperheater was minimized according to the proposal shown in Figure 1. To further optimize the temperature profiles the Multistream-PHE is planned to be extended to a 4-stream apparatus with an additional subcooling section (sec. III) and a second intermediate plate.

Table 5: Symbols.

\begin{tabular}{lll}
\hline Symbol & denotation & SI-unit \\
\hline$A$ & Heat transfer Area & $\mathrm{m}^{2}$ \\
$g$ & Gravitational const. & $\mathrm{m} / \mathrm{s}^{2}$ \\
$G$ & Mass flow density & $\mathrm{kg} / \mathrm{m}^{2} \mathrm{~s}$ \\
$h$ & Enthalpy & $\mathrm{J} / \mathrm{kg}$ \\
$\Delta h_{\mathrm{V}}$ & Heat of evaporation & $\mathrm{J} / \mathrm{kg}$ \\
$L$ & Length & $\mathrm{m}$ \\
$\dot{m}$ & Mass flow & $\mathrm{kg} / \mathrm{s}$ \\
$\mathrm{Nu}$ & Nusselt number & - \\
$p$ & Pressure & $\mathrm{kPa}$ \\
$\dot{q}$ & Heat flux & $\mathrm{W} / \mathrm{m}^{2}$ \\
$T, \vartheta$ & Temperature & $\mathrm{K},{ }^{\circ} \mathrm{C}$ \\
$x$ & Vapour mass fraction & $\mathrm{kg}$ vap $/ \mathrm{kg}_{\mathrm{t}}$ \\
$\alpha$ & Heat transfer coefficient & $\mathrm{W} / \mathrm{m}^{2} \mathrm{~K}$ \\
$\varrho$ & Density & $\mathrm{kg} / \mathrm{m}^{3}$ \\
$\xi$ & Friction pressure coefficient & - \\
\hline
\end{tabular}

Table 6: Indices.

\begin{tabular}{ll}
\hline Symbol denotation \\
\hline $2 \mathrm{ph}$ & two phase, condensation \\
acc & acceleration \\
$\mathrm{c}$ & cooling water \\
cond & condensate, condensing side \\
eq & equivalent \\
exp & experimental \\
het & heterogeneous \\
hom & homogeneous \\
$\mathrm{i}$ & position \\
1 & length \\
liq & liquid \\
$\mathrm{m}$ & averaged \\
man & manifold \\
meas & measured \\
$\mathrm{R}$ & friction \\
sat & saturation \\
stat & static \\
$\mathrm{t}$ & overall, complete \\
vap & vapour \\
$\mathrm{w}$ & wall \\
\hline
\end{tabular}




\section{References}

[1] Yang, Y.Y.; Lio, H.C.; Lin, T.F.: Condensation heat transfer and pressure drop of refrigerant R-134a in a plate heat exchanger. Int. J. Heat Mass Transfer 42 (1999) 993-1006.

[2] Shah, R.K.; Focke, W.W.: Plate heat exchangers and their design theory. Heat Transfer Equipment Design, pp. 913-932, Washington D.C.: Hemisphere 1983.

[3] Boyko, L.D.; Kruzhilin, G.N.: Heat Transfer and Hydraulic Resistance during Condensation of Steam in a Horizontal Tube and in a Bundle of Tubes. Int. J. Heat Mass Transfer 10 (1967) 361.

[4] L. Wang, B. Sunden, Pressure drop analysis of steam condensation in a plate heat exchanger. Heat Transfer Energy. 20 (1999) 71-77.

[5] Lockhart, R.W.; Martinelli, R.C.: Proposed correlation of Data for Isothermal Two-Phase, Two Component Flow in Pipes. Chem. Eng. Proc. 45 (1949) 39-48.

[6] Tribbe, C. and Müller-Steinhagen, H.M.: Gas/liquid flow in plate-andframe heat exchangers - part II: Two-phase multiplier and flow pattern analysis. Heat Transfer Eng. 22 (2001) 12-21.

[7] Grabenstein, V.: Experimentelle Untersuchung und Modellierung der Kondensation in Plattenwärmeübertragern. Diss. Universität Hannover, Fakultät Maschinenbau, 2014.

[8] André, M.: Wärmeübergang bei der Verdampfung von Ammoniak in Plattenwärmeübertragern. Diss., Universität Hannover, Fakultät Maschinenbau, 2004.

[9] Djordjevic, E.M.; Kabelac, S.; Serbanovic, S.P.: Heat Transfer coefficient and pressure drop during refrigerant R134a condensation in a plate heat exchanger. Chem.Pap. - Chem. Zvesti 62 (2008) 78-85.

[10] Martin, H.: Druckverlust und Wärmeübergang in Plattenwärmeübertragern.VDI-Wärmeatlas, pp. 1-7, 10. Ed. Berlin: Springer 2006.

[11] Kakac, S.; Liu, K.: Heat Exchangers Selection, Rating and Thermal Design. BocaRaton: CRC Press 1998.

[12] Akers, W.W.; Deans, H.A.; Crosser, O.K.: Condensing heat transfer within horizonta tubes. Chem. Eng. Prog. S. Ser. 55 (1959) 171-176.

[13] Chisholm, D.: A theoretical basis for the Lockhart-Martinelli correlation for twophase Flow. Int. J. Heat Mass Transfer 10 (1983) 1767-1778.

[14] Bassiouny, M.K.: Experimentelle und theoretische Untersuchungen über Mengenstromverteilung, Druckverlust und Wärmeübergang in Plattenwärmeaustauschern. Fortschr. Ber. VDI R. 6, VDI-Verl. Düsseldorf 1985.

[15] Z. Wang, Z. Zhao, Analysis of performance of steam condensation heat transfer and pressure drop in plate condensers. Heat Transfer Energy. 14 (1993) 32-41. 